\title{
How many lymph nodes should be assessed in patients with gastric cancer? A systematic review
}

\author{
Rajini Seevaratnam $\cdot$ Alina Bocicariu $\cdot$ Roberta Cardoso $\cdot$ \\ Lavanya Yohanathan · Matthew Dixon · Calvin Law • \\ Lucy Helyer · Natalie G. Coburn
}

Received: 28 October 2011/Accepted: 1 June 2012/Published online: 16 August 2012

(c) The International Gastric Cancer Association and The Japanese Gastric Cancer Association 2012

\begin{abstract}
Background Nodal status is one of the most important prognostic factors in gastric adenocarcinoma (GC). As such, it is important to assess an appropriate number of lymph nodes (LNs) in order to accurately stage patients. However, the number of LNs assessed in each GC case varies, and in many cases the number examined per gastric specimen is less than current recommendations.

Purpose We aimed to identify and synthesize findings from all articles evaluating the association of clinicopathological features and long-term outcomes with the number of LNs assessed among GC patients.

Methods Systematic electronic literature searches were conducted using Medline, Embase, and the Cochrane Central Register of Controlled Trials from 1998 to 2009.
\end{abstract}

Electronic supplementary material The online version of this article (doi:10.1007/s10120-012-0169-y) contains supplementary material, which is available to authorized users.

R. Seevaratnam - A. Bocicariu $\cdot$ R. Cardoso $\cdot$ L. Yohanathan M. Dixon · N. G. Coburn

Sunnybrook Research Institute, Sunnybrook Health Sciences

Centre, Toronto, Canada

M. Dixon

Department of Surgery, Maimonides Medical Center,

Brooklyn, USA

C. Law · N. G. Coburn $(\bowtie)$

Division of Surgical Oncology, Sunnybrook Health Sciences Centre, Odette Cancer Centre, Suite T2-60, 2075 Bayview Ave,

Toronto, ON M4N 3M5, Canada

e-mail: natalie.coburn@sunnybrook.ca

L. Helyer

Division of General Surgery, Department of Surgery,

Dalhousie University, Halifax, Canada
Results Twenty-five articles were included in this review. Extensive resection, increased tumor size, and greater TNM staging were all associated with a greater number of LNs assessed. The disease-free survival was longer and recurrence rate was lower in patients with more LNs assessed. Overall survival, as well as survival by TNM and clinical stage, was improved among patients with an increased number of LNs assessed, but much of this appears to be due to stage migration, with the effect more pronounced in more advanced disease.

Conclusion More LNs assessed resulted in less stage migration and possibly better long-term outcomes. Although current guidelines suggest $16 \mathrm{LNs}$ to be assessed, especially in advanced GC, a higher number of LNs should be assessed.

Keywords Gastric cancer - Lymph nodes · Assessment . Survival $\cdot$ Staging

\section{Introduction}

Surgery is the only effective intervention for cure or longterm survival among patients with gastric adenocarcinoma (GC). In areas without screening (i.e., North America and Europe), patients often present late and have a high frequency of nodal involvement [1], with an estimated rate of lymph node (LN) involvement of 3-5\% for T1a; $11-25 \%$ for $\mathrm{T} 1 \mathrm{~b} ; 50 \%$ for $\mathrm{T} 2$; and $83 \%$ for $\mathrm{T} 3$ tumors $[2,3]$. Nodal status is one of the most important independent predictors of patient survival $[4,5]$.

There is international variation in standards for nodal resection in GC. The Japanese Gastric Cancer Association (JGCA) has published detailed guidelines for the pathologic assessment and staging of GC, describing 16 nodal 
compartments classified as N1, N2, and N3 groups. While there is strong support in Asia and some European centers for the more extensive D2 LN dissection, which removes both the $\mathrm{N} 1$ and $\mathrm{N} 2$ nodal groupings, several randomized control trials have failed to demonstrate a survival benefit for this extended surgery, leading to less acceptance of this resection in North America [6, 7]. For example, in the United States, the Intergroup 0116 trial found that only $10 \%$ of patients had the recommended D2 LN dissection; $36 \%$ had a D1 LN dissection; and $54 \%$ had an inadequate D0 LN dissection [8].

An alternative method to determine the extent of $\mathrm{LN}$ resection for a given patient is the "Maruyama Index of Unresected Disease" (MI). Researchers at the National Cancer Center Hospital in Tokyo have documented the disease spread in patients treated by D2 or greater lymphadenectomy in a searchable computerized database, referred to as the "Maruyama Program" [9-11]. This program calculates the probability of positive LNs in the 16 stations, determined by seven variables: age, sex, Borrmann type of tumor, greatest dimension of the tumor as measured on the luminal surface, location of the tumor, tumor depth, and histology. The MI is the sum of the probability of nodal involvement for the nodal stations that were not dissected. An MI of 0 can be achieved in all gastric resections [12] if surgical removal of all 'at risk' nodal stations is performed. A strong correlation between a lower MI and an increase in overall survival (OS) has been demonstrated in American, European, and Asian patients $[8,13,14]$. This has led researchers to assert that better local-regional therapy can favorably affect survival in GC, and that the MI may be a better indicator of adequacy of surgery than a particular lymphadenectomy [13, 14]. Additionally, these analyses show that findings from Asian studies have strong implications for patients in the West, despite the assertion that biologic differences explain the improved survival of GC in the East [2]. Regardless of which resection technique is selected, it appears that there is a complex relationship between the $\mathrm{LN}$ dissection performed, clinical staging, and ultimate patient outcome.

In 1997 the Union International Contre le Cancer (UICC)/American Joint Committee on Cancer (AJCC) recommended, in the 5th edition of their staging manual, that a minimum of $15 \mathrm{LNs}$ be assessed per patient [15]. The recommendation was based on the nodal classification system of $\mathrm{N} 1=1-6$ positive LNs; $\mathrm{N} 2=7-15$ positive LNs; and N3 = more than 15 positive LNs. The cut-off points were derived from retrospective databases [16]. Subsequent examinations [17, 18] have shown superior predictive ability of LN staging based on number of nodes involved rather than the location of nodal involvement. [19]. Part of this superior predictive ability has been attributed to the category N3 ( $>15$ LNs positive), a group with extremely poor prognosis. The 7th edition of the UICC/AJCC staging manual (2010) revised the nodal classification system such that $\mathrm{N} 1=1-2$ positive $\mathrm{LNs}$; $\mathrm{N} 2=3-6$ positive $\mathrm{LNs}$; N3a $=7-15$ positive $\mathrm{LNs}$; and $\mathrm{N} 3 \mathrm{~b}=16$ or more positive LNs [20]. As such, the UICC/ AJCC now recommends that at least $16 \mathrm{LNs}$ be assessed per patient [20]. The staging changes attempt to minimize the impact of surgical dissection on GC staging, and to improve the prognostic ability of $\mathrm{N}$-staging compared to that in the 5th/6th editions [21]. Unfortunately, despite the changes to simplify staging, the number of LNs assessed in each GC case varies, and in many cases, the number reported per specimen is less than current recommendations $[15,22]$. In the United States, a median of only 10 nodes per patient were assessed, and $9 \%$ had no LN assessment at all. Only $29 \%$ of patients had $>15$ LNs assessed [23-25].

An LN ratio (LNR) has also been proposed and many international groups have examined the utility of an LNR for the prognosis of $\mathrm{GC}$, finding this more predictive than simple analysis of the number of positive LNs [26-28]. However, most studies have excluded patients with fewer than 15 LNs examined, and no uniform cut-off points have been identified to date. Although an LNR does mitigate the effects of stage migration somewhat, its utility in patients in whom fewer than 15 LNs were assessed has not been proven.

Studies have shown that stage migration occurs in patients with a lower number of LNs examined, creating inaccuracies in survival predictions [18, 29-31]. In addition to the importance of nodal status as a prognostic factor in GC, it has been suggested that inadequate LN assessment directly affects patient survival for the worse $[32,33]$. Therefore, the purpose of this review was to identify and synthesize findings from all articles evaluating both predictors of nodal harvest and long-term outcomes based on the number of LNs assessed.

\section{Methods}

\section{Data sources}

Electronic literature searches were conducted using Medline and Embase from January 1, 1998, to December 31, 2010 according to the search algorithm presented in electronic Appendix A. Search terms included: exp Stomach Cancer/or [((gastric or stomach) adj1 cancer\$) or ((gastric or stomach) adj1 carcinoma) or ((gastric or stomach) adj1 adenocarcinoma) or ((gastric or stomach) adj1 neoplasm\$)).mp.] and [number of lymph nodes or lymph node assessment or lymph node examination or total lymph node count $]$ and $[(($ negative or resection $)$ adj2 margin\$).mp. or 
exp frozen section/or exp GASTRECTOMY/or ((gastric or stomach) adj2 resect\$).mp. [mp = title, abstract, subject headings, heading word, drug trade name, original title, device manufacturer, drug manufacturer name] or omentectom\$.mp. or multivisceral resection\$.mp.] and [clinical trial/or controlled clinical trial/or exp comparative study/or meta analysis/or multicenter study/or exp practice guideline/or randomized controlled trial/] not [Case Report/or review]. A separate search of the Cochrane Central Register of Controlled Trials (1985-2010) was performed using the search term "gastric cancer". No attempt was made to locate unpublished material.

\section{Study selection and review process}

To be eligible, studies had to meet the following criteria: (1) investigated number of LNs examined in newly (not recurrent) diagnosed patients with histopathology-confirmed gastric adenocarcinoma; (2) reported long-term outcomes and clinicopathological factors based on the number of LNs assessed; (3) patients had a pathological examination of the surgical specimens and LNs dissected; (4) involved human patients with a minimum of 30 patients; and (5) published in peer reviewed journals in English. Studies were excluded according to the following criteria: (1) studies that did not provide short- or long-term trial outcomes; (2) involved animals and/or ex vivo samples; (3) involved patients with mixed cancer with no separate analysis of GC subjects; and (4) review articles, meta-analyses, abstracts, conference proceedings, editorials/letters, and case reports. All electronic search titles, selected abstracts, and full-text articles were independently reviewed by a minimum of two reviewers (N.C., R.S., R.C.). Disagreements on study inclusion/exclusion were resolved with a consensus meeting.

Data extraction and analysis

A systematic approach to data extraction was used to produce a descriptive summary of participants, interventions, and study findings. Data abstracted included the study type, number of patients, patient characteristics, resection margin status, number of LNs removed, number of positive LNs, and follow-up time. Data on associations with clinicopathological factors (resection type, tumor location, tumor size, TNM stage, and clinical stage) and the number of assessed LNs were extracted. Disease-free survival, recurrence rate, overall survival, and survival by subgroups (TNM and clinical stage) relating to the number of LNs assessed were extracted. The first reviewer (A.B.) independently extracted the data and a second reviewer (R.S.) checked the data extraction. No attempt was made to contact authors for additional information.

\section{Results}

Literature search

A total of 3,608 titles/abstracts were identified from the electronic searches and reference lists for preliminary review. After the removal of duplicates and screening for relevant titles and abstracts, a total of 52 articles were identified as pertaining to the examination of LN number and long-term outcomes, and these were submitted for a full-text review. A total of 25 retrospective articles [5, 18, 23-25, 29-31, 34-50] involving 74,228 patients were included in this review (Fig. 1). The descriptive characteristics of each included study are presented in Table 1.

Clinicopathological factors and the number of LNs assessed

Details on the various clinicopathological factors associated with the number of LNs assessed are presented in electronic Appendices B-D. Five studies [5, 24, 31, 35, 38] reported significant associations between increased surgical resection (extended dissection or total gastrectomy) and an increased number of LNs assessed (Table 2). Three studies found an association between tumor location (distal tumors in two studies, and middle or upper-third tumors in one study) and an increased number of assessed LNs [35, 38, 43], whereas four studies did not [5, 31, 44, 48] (Table 2). Increased tumor size was significantly associated with a greater number of assessed LNs in 3 studies [35, 38, 48], while one study reported no significant relationship [31]. Four studies found a significant relationship between advanced $\mathrm{T}$ stage and increased number of LNs assessed

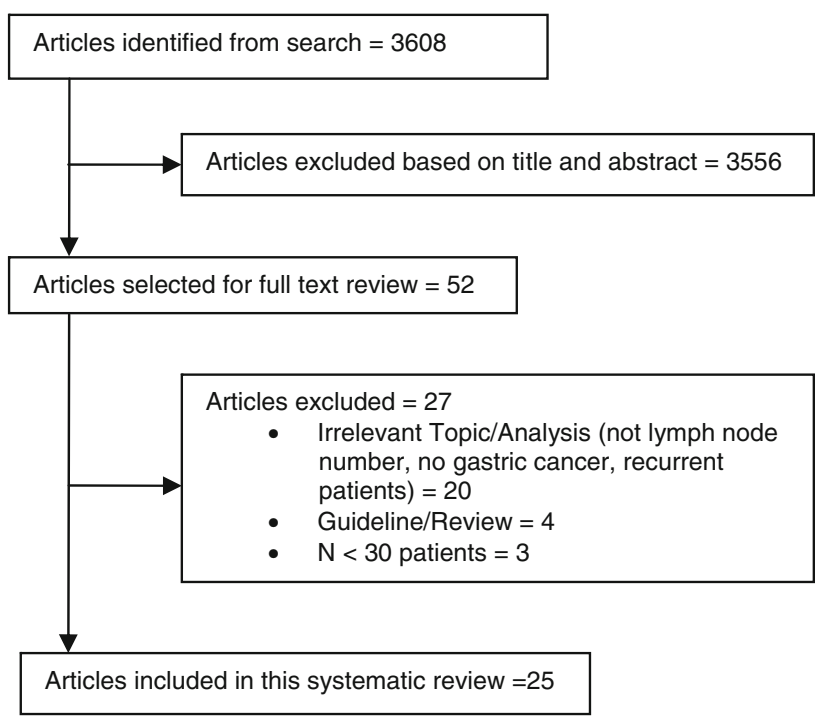

Fig. 1 Article selection flow 


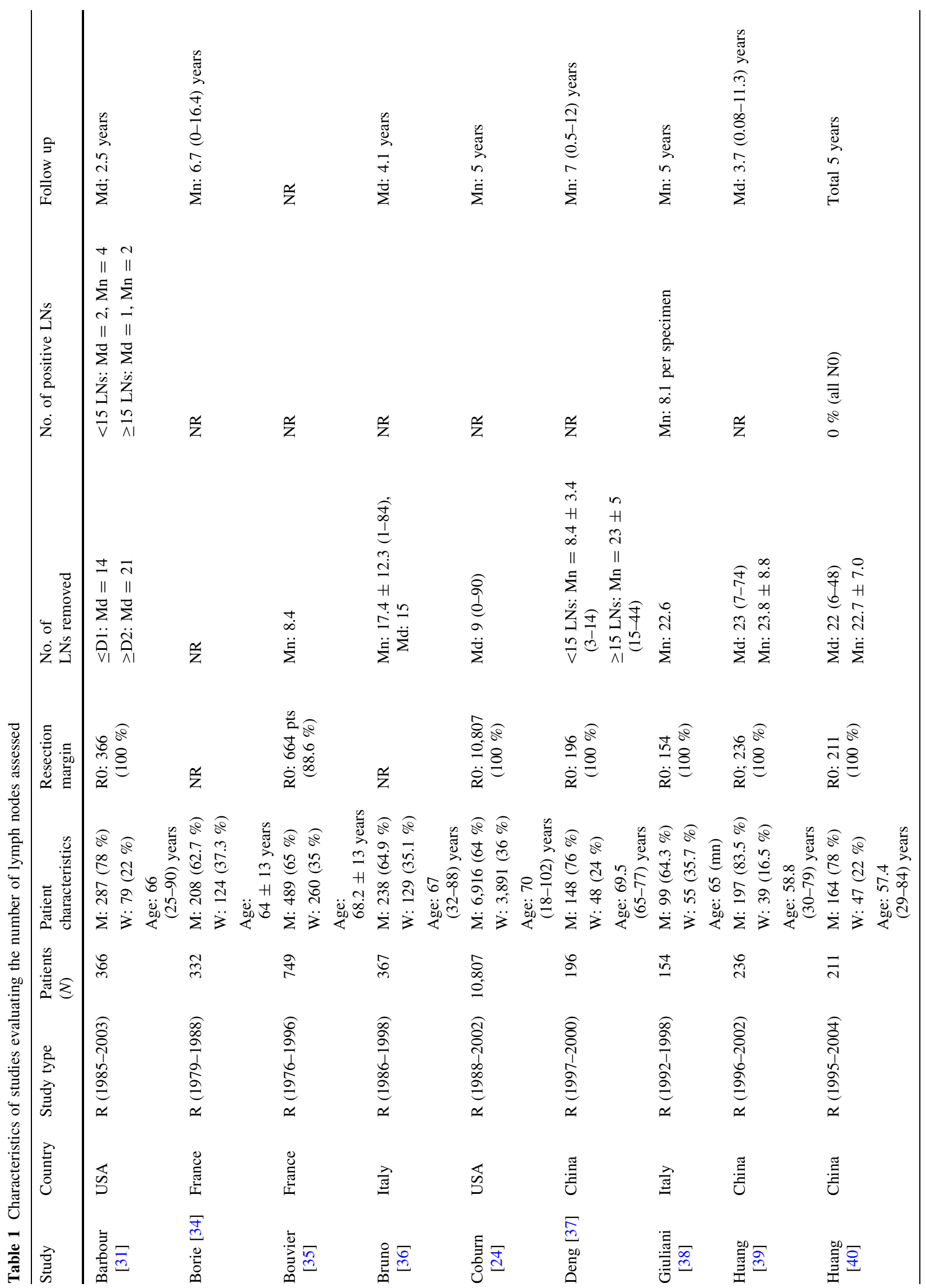




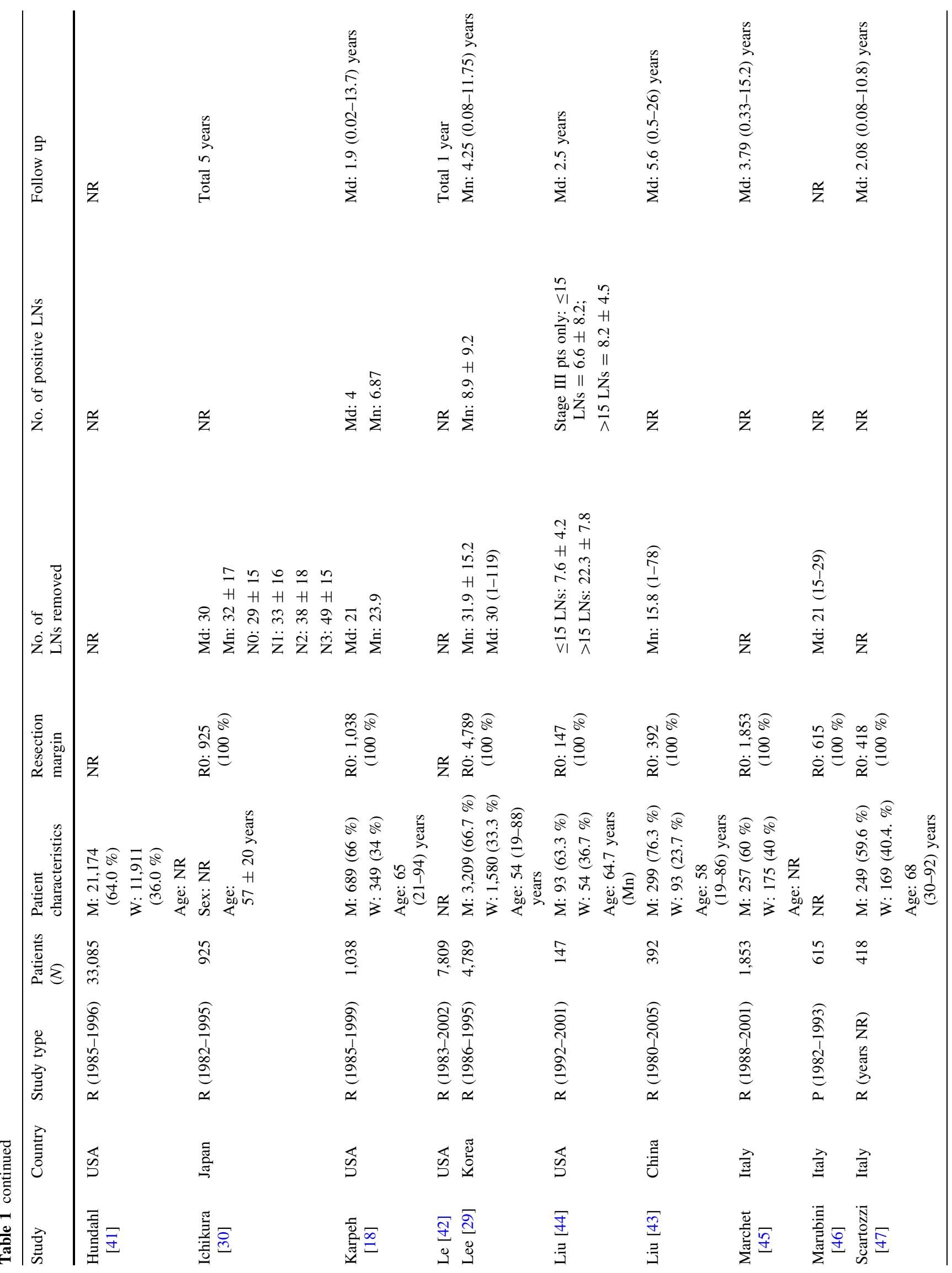




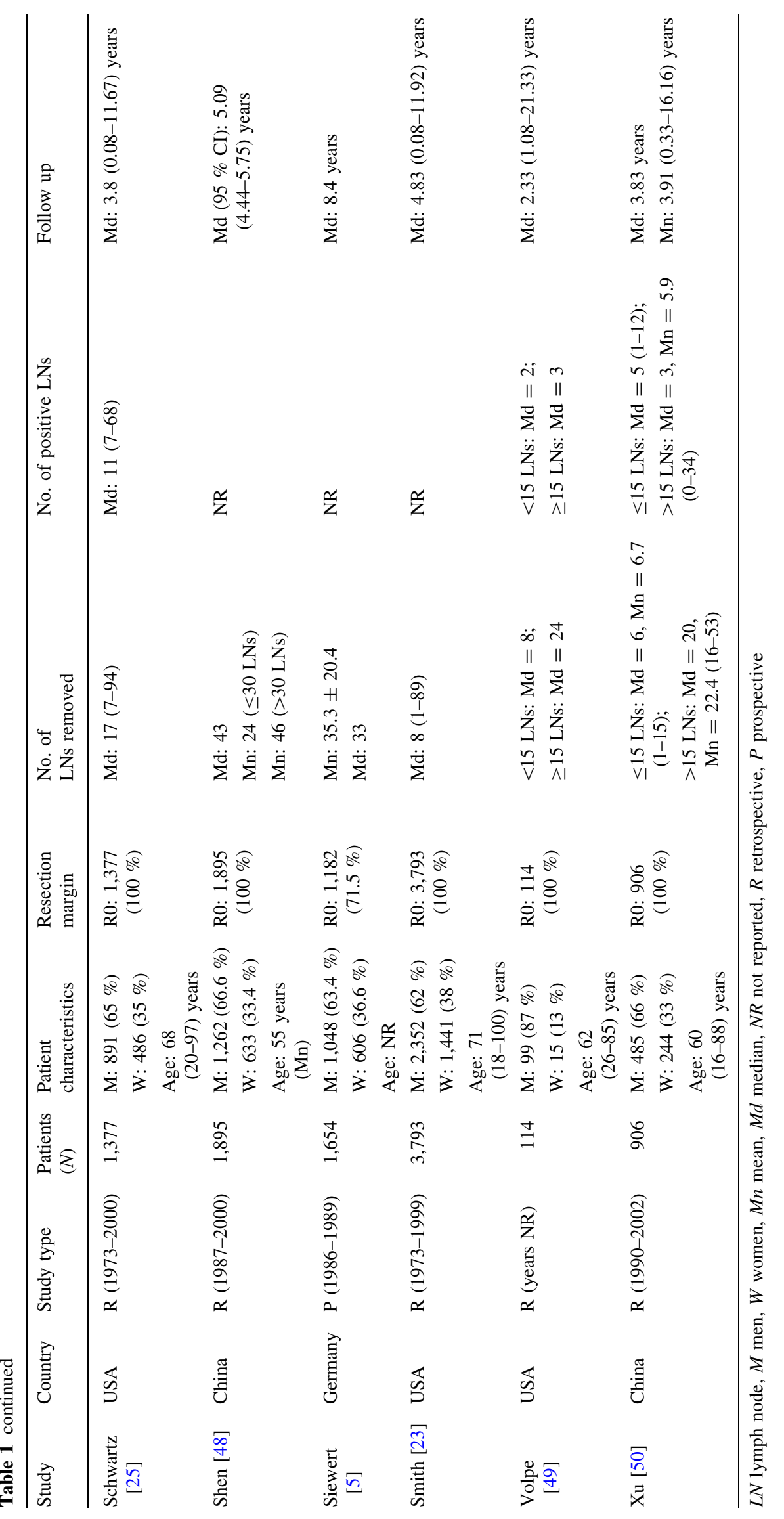


[24, 29, 35, 44]; six studies found a significant association between advanced $\mathrm{N}$ stage and increased number of assessed LNs [5, 23, 31, 43, 44, 48]; and two studies found a significant association between advanced clinical stage and increased number of LNs assessed [31, 44].

Recurrence and disease-free survival and the number of lymph nodes assessed

Disease-free survival (DFS) and/or recurrence rate was reported in 3 studies [37, 40, 47] (Table 3). In two studies, DFS was significantly longer in patients with a greater number of assessed LNs [37, 47], regardless of whether the patient was node-negative or node-positive [47]. Local recurrence was significantly lower in patients with a higher number of LNs assessed [47]. The recurrence rate was also lower among patients with more LNs assessed according to $\mathrm{T}$ stage [40]. If recurrence was observed, median overall survival (OS) with recurrence was significantly longer in patients with at least $15 \mathrm{LNs}$ assessed [37]. In patients with positive nodes, DFS was still significantly longer when more than 25 LNs were assessed [47].
Overall survival and the number of LNs assessed

OS was reported in 18 studies [5, 24, 25, 31, 34, 36-40, 42-47, 49, 50] (Tables 4, 5, 6). Improved OS was significantly associated with an increased number of LNs assessed in just over half of the studies (10 of 18) [24, 25, 34, 36, $37,39,40,42,46,47]$. Studies investigating OS in only N0 (Table 3 ) or $\mathrm{N}+$ (Table 6) cohorts are shown in separate Tables, as stage migration is a factor in these cohorts. Four studies [31, 39, 40, 50] reported OS by $\mathrm{T}$ stage for number of LNs assessed (Table 7). One study found a significant relationship with improved OS for all $\mathrm{T}$ stages with an increased number of assessed LNs [40], while other studies only found significant associations for $\mathrm{T} 2$ patients [31], or T4 patients [39]. One study found no significant association between the number of LNs assessed and survival rates according to $\mathrm{T}$ stage [50].

Eleven studies [18, 24, 30, 31, 38, 39, 43, 45, 47, 48, 50] reported survival rates by $\mathrm{N}$ stage (Table 8 ), and found a significant relationship with improved survival among N0 patients $[24,30,31,38,45,50], \mathrm{N} 1$ patients [18, 31, 39, 45, $50]$, and $\mathrm{N} 2$ patients $[18,31,39,45,48,50]$, with an

Table 2 Clinicopathological factors associated with the number of LNs assessed

\begin{tabular}{|c|c|c|c|c|c|c|c|}
\hline Study & Number of LNs assessed & $\begin{array}{l}\text { Resection } \\
\text { type }\end{array}$ & $\begin{array}{l}\text { Tumor } \\
\text { location }\end{array}$ & $\begin{array}{l}\text { Tumor } \\
\text { size }\end{array}$ & T stage & $\mathrm{N}$ stage & $\begin{array}{l}\text { Clinical } \\
\text { stage }\end{array}$ \\
\hline Barbour [31] & $<15$ LNs: 116 pts $(32 \%)$ vs. $\geq 15$ LNs: $250(68 \%)$ & $\mathrm{Y}^{\mathrm{a}}$ & $\mathrm{N}$ & $\mathrm{N}$ & $\mathrm{N}$ & $\mathrm{Y}$ & $\mathrm{Y}$ \\
\hline Bouvier [35] & $\begin{array}{l}0 \text { LNs: } 87 \text { pts }(11.6 \%) \text { vs. } 1-9 \text { LNs: } 359 \text { pts }(47.9 \%) \text { vs. } \\
\text { 10-14 LNs: } 171 \text { pts }(22.8 \%) \text { vs. } \geq 15 \text { LNs: } \\
132 \text { pts }(17.6 \%)\end{array}$ & $\mathrm{Y}^{\mathrm{b}}$ & $\mathrm{Y}$ & $\mathrm{Y}$ & $\mathrm{Y}$ & - & - \\
\hline Coburn [24] & $<15$ LNs: 7,673 pts $(71 \%)$ vs. $\geq 15$ LNs: 3,134 pts $(29 \%)$ & $\mathrm{Y}^{\mathrm{b}}$ & - & - & $\mathrm{Y}$ & - & - \\
\hline Giuliani [38] & 15-26 LNs: 115 pts $(74.7 \%)$ vs. $>26$ LNs: 39 pts $(25.3 \%)$ & $\mathrm{Y}^{\mathrm{b}}$ & $\mathrm{Y}$ & $\mathrm{Y}$ & $\mathrm{N}$ & - & - \\
\hline Huang [39] & $\begin{array}{l}<15 \text { LNs: } 36 \text { pts }(15.3 \%) \text { vs. } 15-19 \text { LNs: } 43 \text { pts }(18.2 \%) \\
\text { vs. } 20-24 \text { LNs: } 62 \text { pts }(26.3 \%) \text { vs. } 25-29 \text { LNs: } 40 \text { pts }(16.9 \%) \\
\text { vs. } \geq 30 \text { LNs: } 55 \text { pts }(23.3 \%)\end{array}$ & - & - & - & $\mathrm{N}$ & - & - \\
\hline Lee [29] & $\begin{array}{l}<15 \text { LNs: } 424 \text { pts }(9.9 \%) \text { vs. } 15-29 \text { LNs: } 1,826(42.8 \%) \\
\text { vs. } \geq 30 \text { LNs: } 2,020 \text { pts }(47.3 \%)\end{array}$ & - & - & - & $\mathrm{Y}$ & - & - \\
\hline Liu [44] & $\leq 15$ LNs: 124 pts $(84.4 \%)$ vs. $>15$ LNs: 23 pts $(15.6 \%)$ & - & $\mathrm{N}$ & - & $\mathrm{Y}$ & $\mathrm{Y}$ & $\mathrm{Y}$ \\
\hline Liu [43] & $\begin{array}{l}\text { <15 LNs: } 208 \text { pts }(53.1 \%) \text { vs. } 15-25 \text { LNs: } 125 \text { pts }(31.9 \%) \\
\text { vs. }>25 \text { LNs: } 59 \text { pts }(15.1 \%)\end{array}$ & - & $\mathrm{Y}$ & - & - & $\mathrm{Y}$ & - \\
\hline Shen $[48]$ & $\leq 30$ LNs: $432(22.8 \%)$ vs. $>30$ LNs: $1,463(77.2 \%)$ & - & $\mathrm{N}$ & $\mathrm{Y}$ & - & $\mathrm{Y}$ & - \\
\hline Siewert [5] & $\begin{array}{l}\leq 25 \text { LNs: } 558 \text { pts }(33.7 \%) \text { vs. }>25 \text { LNs: } \\
1,096 \text { pts }(66.3 \%)\end{array}$ & $\mathrm{Y}^{\mathrm{a}}$ & $\mathrm{N}$ & - & $\mathrm{N}$ & $\mathrm{Y}$ & $\mathrm{N}$ \\
\hline Smith [23] & $\begin{array}{l}\text { 1-9 LNs: } 2,143 \text { pts }(56.5 \%) \text { vs. } 10-19 \text { LNs: } 1,153 \text { pts } \\
(30.4 \%) \text { vs. } 20-29 \text { LNs: } 215 \text { pts }(5.7 \%) \text { vs. } 30-39 \text { LNs: } \\
215 \text { pts }(5.7 \%) \text { vs. }>40 \text { LNs: } 67 \text { pts }(1.8 \%)\end{array}$ & - & - & - & $\mathrm{Y}^{\mathrm{c}}$ & & - \\
\hline
\end{tabular}

Please see electronic Appendix $\mathrm{C}$ for details

$Y$ yes, $N$ no, - not reported, pts patients

a $<$ D2 versus $\geq$ D2

b Subtotal gastrectomy vs total gastrectomy

c $\mathrm{T}$ stage and $\mathrm{N}$ stage combined 


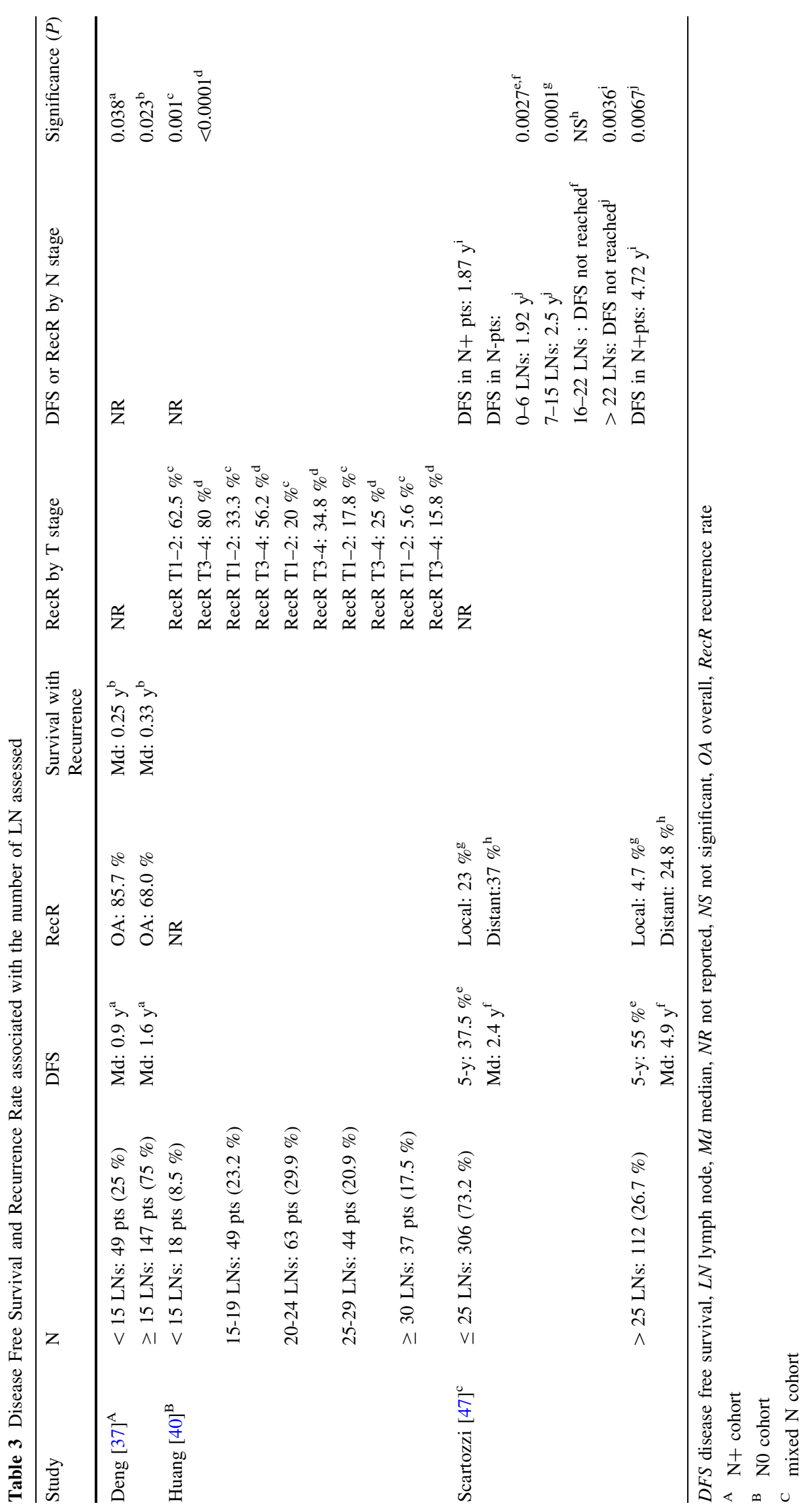


Table 4 Overall survival rates associated with the number LN assessed for mixed N-stage cohorts

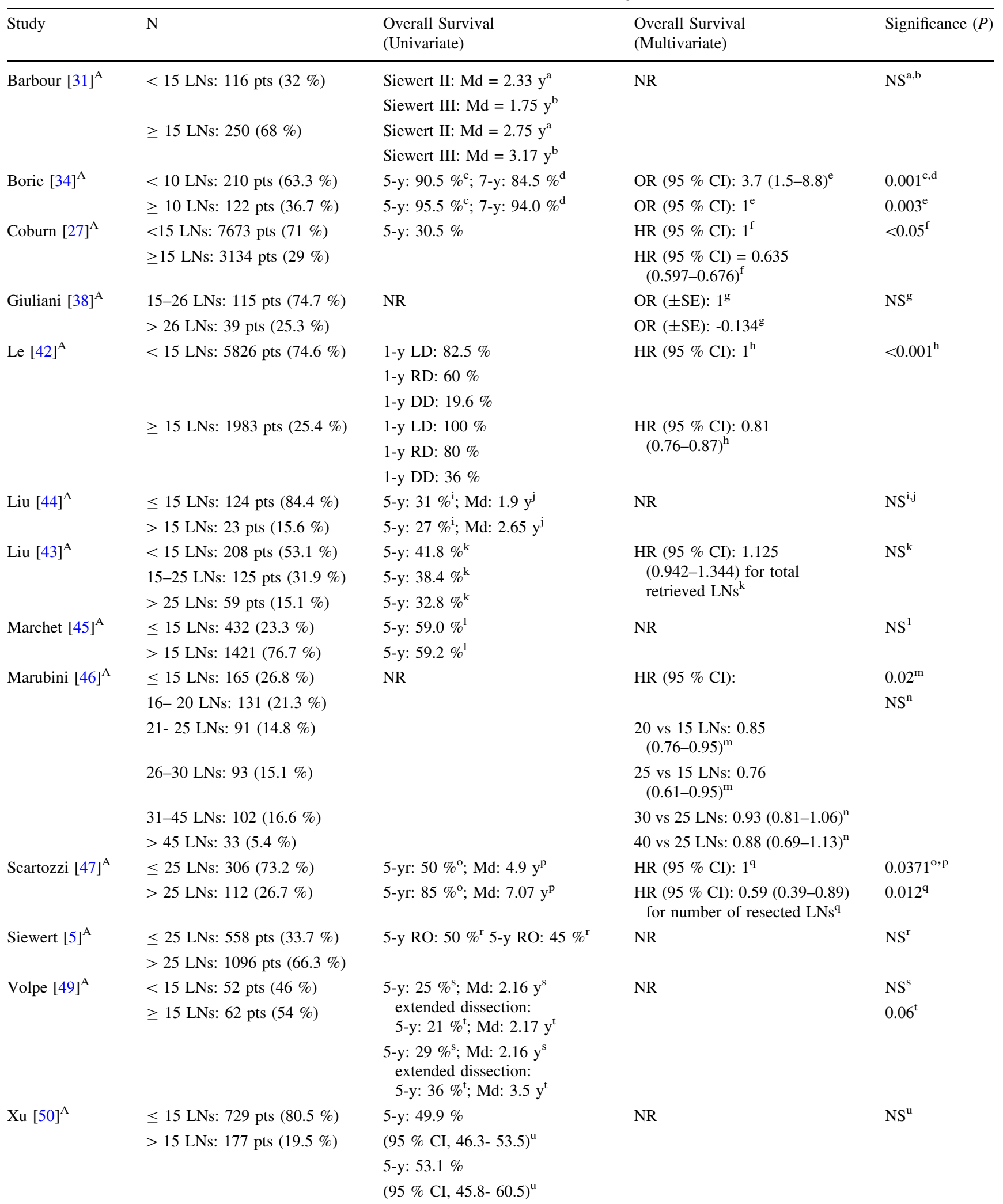

$C I$ confidence interval, $H R$ hazard ratio, $M d$ median, $N R$ not reported, $N S$ not significant, $O D$ odds ratio, $L D$ local disease, $R D$ regional disease, $D D$ distant disease

A mixed $\mathrm{N}$ cohort 
Table 5 Overall survival rates associated with the number LN assessed for N0 cohorts

\begin{tabular}{|c|c|c|c|c|}
\hline Study & $\mathrm{N}$ & Overall Survival & Overall Survival (Multivariate) & Significance $(P)$ \\
\hline Bruno $[36]^{\mathrm{A}}$ & $\begin{array}{l}\leq 15 \text { LNs: } 301 \text { pts }(82 \%) \\
>15 \text { LNs: } 66 \text { pts }(18 \%)\end{array}$ & $\begin{array}{l}5-\mathrm{y}: 59 \%^{\mathrm{a}} \\
5-\mathrm{y}: 82 \%^{\mathrm{a}}\end{array}$ & NR & $<0.001^{\mathrm{a}}$ \\
\hline Huang $[39]^{\mathrm{A}}$ & $\begin{array}{l}\text { < } 15 \text { LNs: } 36 \text { pts }(15.3 \%) \\
\text { 15-19 LNs: } 43 \text { pts }(18.2 \%) \\
\text { 20-24 LNs: } 62 \text { pts }(26.3 \%) \\
\text { 25-29 LNs: } 40 \text { pts }(16.9 \%) \\
\geq 30 \text { LNs: } 55 \text { pts }(23.3 \%)\end{array}$ & $\begin{array}{l}\text { 5-y: } 19.4 \%^{\mathrm{b}} \\
5-\mathrm{y}: 25.0 \%^{\mathrm{b}} \\
\text { 5-y: } 37.4 \%^{\mathrm{b}} \\
\text { 5-y: } 45.0 \%^{\mathrm{b}} \\
5-\mathrm{y}: 38.2 \%^{\mathrm{b}}\end{array}$ & $\begin{array}{l}\mathrm{RR}(95 \% \mathrm{CI}): 0.959 \\
\quad(0.941-0.977) \\
\text { for number of total } \mathrm{LNs}^{\mathrm{c}}\end{array}$ & $\begin{array}{l}0.0009^{\mathrm{b}} \\
<0.05^{\mathrm{c}}\end{array}$ \\
\hline Huang $[40]^{\mathrm{A}}$ & $\begin{array}{l}<15 \text { LNs: } 18 \text { pts }(8.5 \%) \\
\text { 15-19 LNs: } 49 \text { pts }(23.2 \%) \\
\text { 20-24 LNs: } 63 \text { pts }(29.9 \%) \\
\text { 25-29 LNs: } 44 \text { pts }(20.9 \%) \\
\geq 30 \text { LNs: } 37 \text { pts }(17.5 \%)\end{array}$ & $\begin{array}{l}\text { 5-y: } 43.2 \%^{\mathrm{d}} \\
\text { 5-y: } 76.8 \%^{\mathrm{d}} \\
\text { 5-y: } 84.5 \%^{\mathrm{d}} \\
\text { 5-y: } 90.6 \%^{\mathrm{d}} \\
\text { 5-y: } 94.5 \%^{\mathrm{d}}\end{array}$ & $\begin{array}{l}\mathrm{RR}(95 \% \mathrm{CI}): 0.527 \\
(0.399-0.695) \\
\text { for number of resected } \mathrm{LNs}^{\mathrm{e}}\end{array}$ & $\begin{array}{l}<0.0001^{\mathrm{d}} \\
<0.05^{\mathrm{e}}\end{array}$ \\
\hline
\end{tabular}

$R R$ relative risk

A N0 cohort

increased number of LNs assessed. Only one study found this relationship to be significant among N3 patients [39]. Scartozzi et al. [47] found this relationship significant for all node-positive patients, whereas Liu et al. [43] did not find any significant associations between number of LNs assessed and survival according to $\mathrm{N}$ stage.

Among the three studies [5, 23, 25] investigating OS according to combined $\mathrm{T}$ and $\mathrm{N}$ stage (Table 9), two found a significant relationship between improved OS and increased number of LNs assessed irrespective of $\mathrm{T}$ and $\mathrm{N}$ stage [23, 25], whereas one study found this association significant only at specific stages (T2N1, T3N0, T2N2, and T4N0) [5]. OS by clinical stage was reported in 10 studies [5, 18, 24, 29, 30, 35, 39, 41, 44, 49] (electronic Appendix E). Two studies found a significant relationship with improved OS among patients with stage I GC and increased number of LNs assessed [24, 30]; four studies found this association significant among stage II patients [5, 24, 39, 49]; seven studies found this relationship significant among stage III patients [5, 18, 24, 29, 30, 39, 44]; and three studies found this association significant among stage IV patients [18, 24, 39]. An increased relative risk of death was reported among patients with fewer LNs assessed in a combined analysis of stage I and II patients [35]. Although one study did not report $P$ values, a visible trend was found for improved OS among patients with increased numbers of assessed LNs among all 4 stages [41].

\section{Discussion}

Nodal status is one of the most important prognostic factors in GC [5]. To ensure that patients are accurately staged and provided the optimal treatment, it is important to assess an adequate number of LNs. Currently the UICC/AJCC recommends that at least $16 \mathrm{LNs}$ be assessed per patient [22]. However, the number of LNs assessed in each GC case varies; in the United States, the median number assessed is 10 [24, 51], while in Asia, it is generally three to four times higher [29, 39, 40, 48]. This significant variation may affect both staging accuracy and patient survival. A significant problem with the current staging system, as well as with the 5th and 6th UICC/AJCC editions, is stage migration $[15,21,22]$. If an inadequate number of LNs are assessed, a patient may be inappropriately considered "node-negative" or designated a lower $\mathrm{N}$ stage and therefore classified as a lower overall stage; however, these patients have a worse survival than patients who were classified appropriately through a thorough LN assessment. Additionally, a classification of N3 (using the 5 th or 6th UICC/AJCC staging editions [15, 22]) could not be given unless $16 \mathrm{LNs}$ were positive. In the current 7th UICC/AJCC staging edition [20], the minimum recommendation has now been increased to 16 , which addresses the above issue and also allows for the classification of the new $\mathrm{N} 3 \mathrm{~b}$ category (16 or more positive LNs) [20]. However, the likelihood of a patient being staged as $\mathrm{N} 3 \mathrm{~b}$, if only the minimum number of $16 \mathrm{LNs}$ are assessed, is obviously lower than that if more than 16 LNs are assessed. Studies of surgical dissections have shown that a mean of 26 LNs (range 8-55) were removed with a D1 LN dissection, whereas 37.4 LNs (15-72) were included in a D2 LN dissection [52]. Roukos et al. [52] also reported that the number of nodes found at each station had high variation in nodal yields, and many stations contained no LNs despite adequate resection and thorough pathological examination. Thus, it is difficult to define an ideal number of LNs in a surgical specimen, and the type of LN dissection may significantly affect the number of LNs assessed. 
Table 6 Overall survival rates associated with the number $\mathrm{LN}$ assessed for $\mathrm{N}+$ cohorts

\begin{tabular}{|c|c|c|c|c|}
\hline Study & $\mathrm{N}$ & Overall Survival & Overall Survival (Multivariate) & Significance $(P)$ \\
\hline Deng $[37]^{\mathrm{A}}$ & $\begin{array}{l}<15 \text { LNs: } 49 \text { pts }(25 \%) \\
\geq 15 \text { LNs: } 147 \text { pts }(75 \%)\end{array}$ & $\begin{array}{l}\text { 5-y Median: } 1.6 \mathrm{y}^{\mathrm{a}} \\
\text { 5-y Median: } 4.08 \mathrm{y}^{\mathrm{a}}\end{array}$ & NR & ${ }^{\mathrm{a}}<0.001$ \\
\hline Schwarz $[28]^{\mathrm{A}}$ & $\begin{array}{l}\text { 7-9 LNs: \# of pts NR } \\
\text { 10-15 LNs: \# of pts NR } \\
\text { 16-19 LNs: \# of pts NR } \\
\text { 20-24 LNs: \# of pts NR } \\
\text { 25-29 LNs: \# of pts NR } \\
\text { 30-39 LNs: \# of pts NR } \\
\geq 40 \text { LNs: \# of pts NR }\end{array}$ & $\begin{array}{l}<15 \text { LNs vs } \geq 15 \text { LNs: } 3-y \\
=15 \% \text { vs } 20 \%^{\mathrm{b}} \\
<25 \text { LNs vs } \geq 25 \text { LNs: } 3-\mathrm{y} \\
=10 \% \text { vs } 21 \%^{\mathrm{c}} \\
<30 \text { LNs vs } \geq 30 \text { LNs: } 3-\mathrm{y} \\
=12 \% \text { vs } 21 \%^{\mathrm{d}} \\
<40 \text { LNs vs } \geq 40 \text { LNs: } 3-\mathrm{y} \\
=15 \% \text { vs } 15 \%^{\mathrm{e}}\end{array}$ & $\begin{array}{l}\mathrm{RR}(95 \% \mathrm{CI}): 0.968(0.960-0.976) \\
\text { for number of LNs examined }^{\mathrm{f}}\end{array}$ & $\begin{array}{l}0.0005^{\mathrm{b}} \\
0.0020^{\mathrm{c}} \\
0.0062^{\mathrm{d}} \\
\mathrm{NS}^{\mathrm{e}} \\
<0.0001^{\mathrm{f}}\end{array}$ \\
\hline
\end{tabular}

$N R$ not reported, $R R$ relative risk

A $\mathrm{N}+$ cohort

Stage migration confounds comparisons of survival across centers and countries in the evaluation of surgical techniques, adjuvant treatments, and the conduct of trials. However, over and above stage migration, authors suggest there may be an actual survival benefit from an extensive lymphadenectomy [5, 44, 47, 49]. Thus, we performed a systematic review to examine clinicopathological factors associated with the assessment of higher numbers of LNs, as well as the outcomes of these assessments based on the number of LNs assessed. While other overviews have been published, to our knowledge, this is the first systematic review to address this issue.

Clinicopathological factors associated with number of LNs assessed

The results of the present systematic review show that patients with a larger tumor size, more advanced disease, or those who had a more extensive lymphadenectomy were likely to have more LNs assessed (Table 1, Appendix C-E). This can either be attributed to the surgeon performing a more extensive primary resection which would include more LNs, or a more thorough examination of the specimen by the pathology team for more advanced cancers. Additionally, with more advanced cancers, LNs may be grossly positive, and thus more easily identified during specimen processing than microscopically involved or uninvolved LNs. For example, as only $43 \%$ of pathologists in a recent survey reported using fat-clearing solutions, such as acetic acid, LNs that are not grossly involved and thus smaller may be missed [53]. Although some studies found an association with tumor location and the number of LNs assessed, this relationship was unclear, as two articles reported that patients with tumors in the distal stomach were likely to have more LNs assessed [38, 43], while another article reported that tumors in the middle or upper-third of the stomach allowed for a greater number of LNs to be assessed [35]. Heterogeneity in surgical techniques among these studies may confound these results. Furthermore, these findings contradict studies showing more LNs are assessed in patients having a more extensive surgical resection (total vs subtotal gastrectomy) [5, 24, 31, 35, 38].

Recurrence and disease-free survival and the number of lymph nodes assessed

The three articles reporting DFS in the context of LN assessment [37, 40, 47] showed longer times to recurrence when more LNs were assessed. Scartozzi et al. [47] reported a remarkable decrease in local recurrence, from $23 \%$ in patients with $\leq 25 \mathrm{LNs}$ assessed compared with $4.7 \%$ in patients with $>25$ LNs assessed. It has been hypothesized that the removal of additional LNs results in better locoregional control. For example, in the 15-year analysis of the Dutch D1/D2 randomized controlled trial (RCT), local recurrence was $22 \%$ in the D1 group, compared with $12 \%$ in the D2 group; while regional recurrence was $19 \%$ in the D1 group, and $13 \%$ in the D2 group $(P=0.015)$ [54]. However, because Huang et al. [40] explored node- negative patients only, and Scartozzi et al. [47] explored T2-3 N1-3 and T3N0 patients only, it is likely that the main effect they measured was that of stage migration.

\section{Stage migration}

Studies in which survival is stratified based upon the determination of $\mathrm{N}$ stage will suffer from stage migration as more LNs are assessed (Tables 7, 8, 9). Additionally, if a study has limited the cohort under examination to nodenegative or node-positive patients only, stage migration 


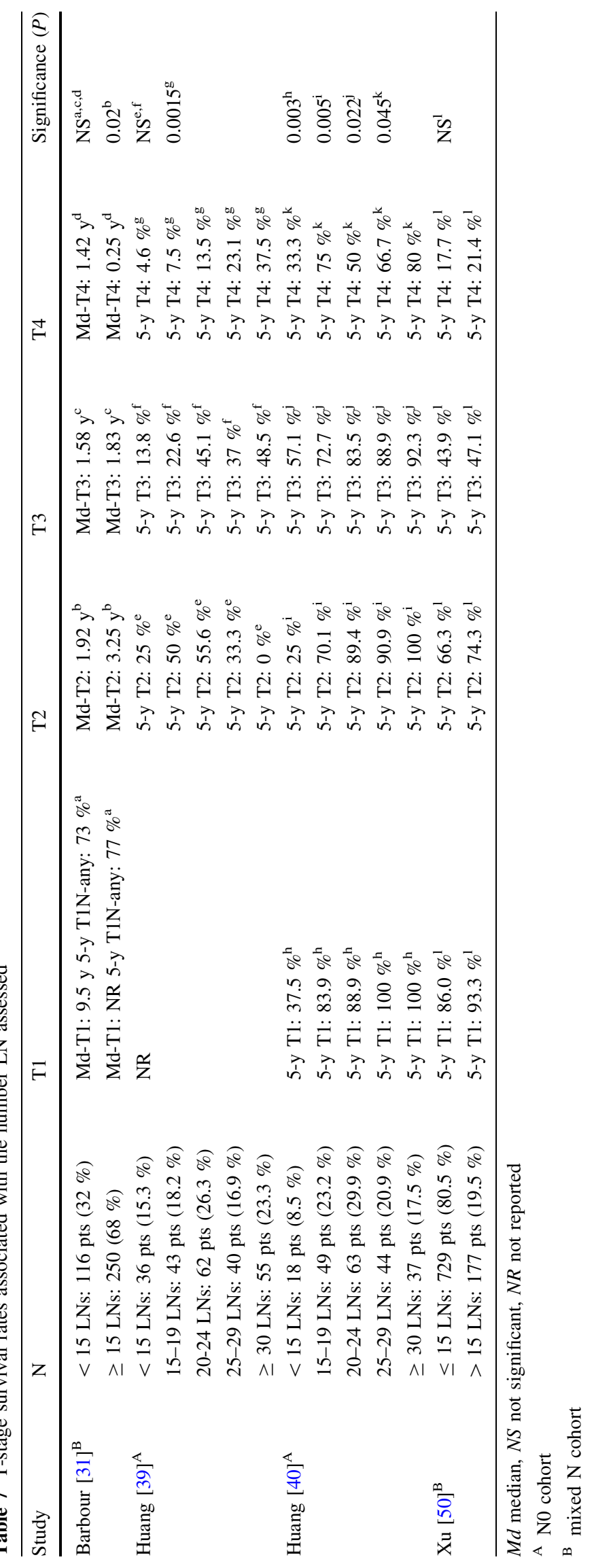




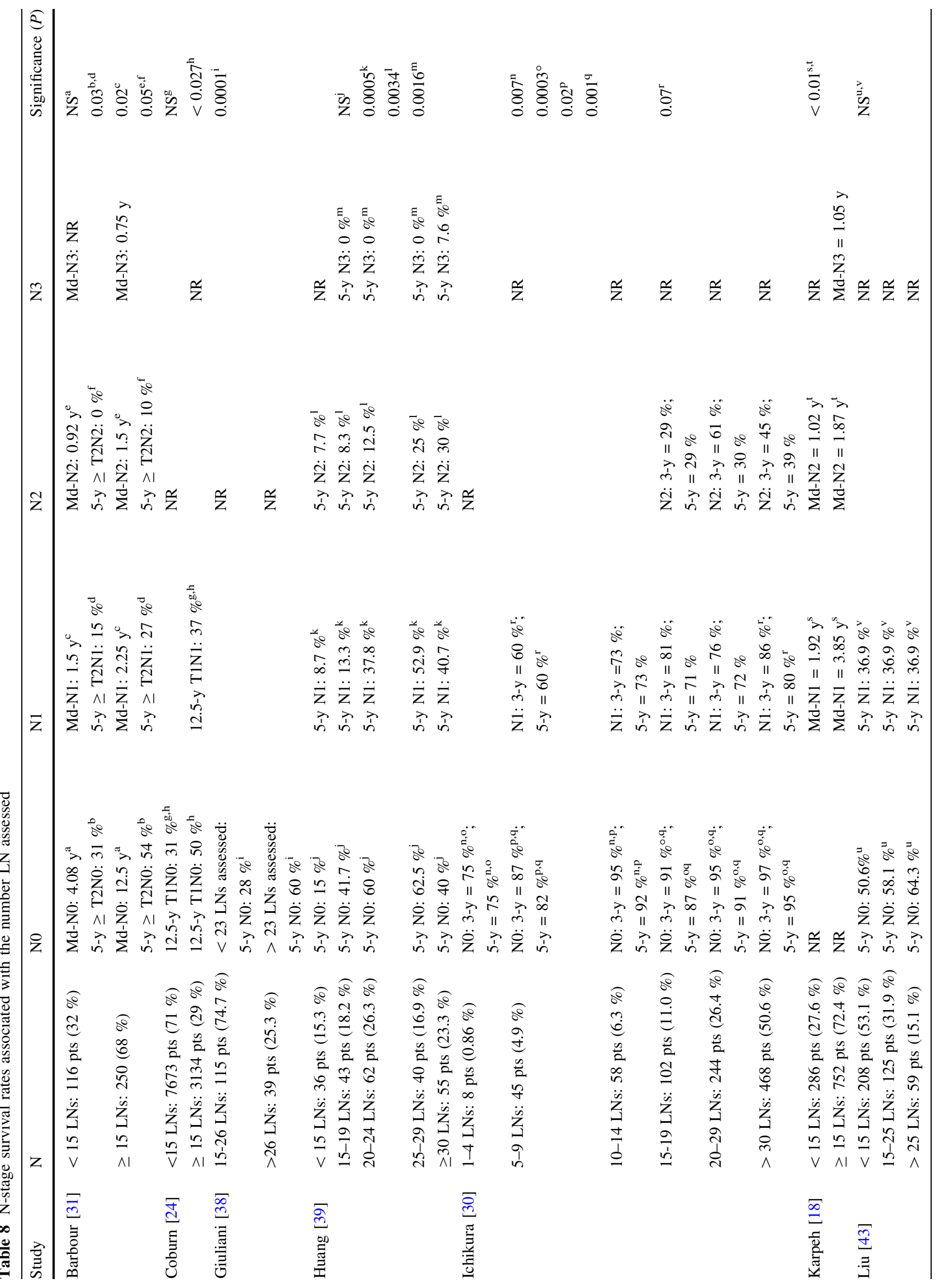




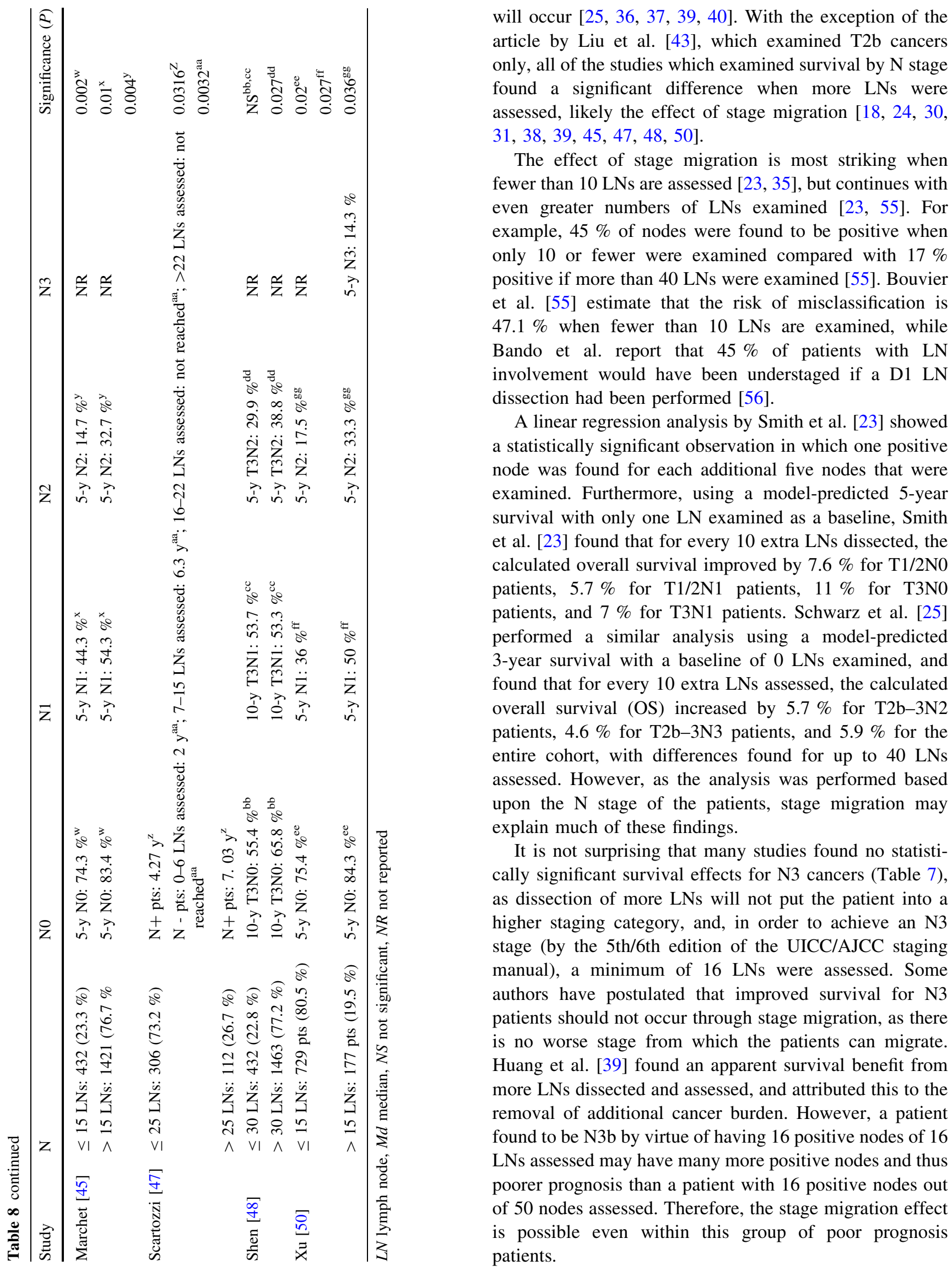


Table 9 Combined TN stage survival rates associated with the number of LNs assessed

\begin{tabular}{|c|c|c|c|c|}
\hline Study & $\mathrm{N}$ & Survival by combined TN stage & & Significance \\
\hline $\begin{array}{c}\text { Schwarz } \\
{[25]}\end{array}$ & $\geq 40$ LNs: & $\begin{array}{l}\text { 3-years T2bN2: } 10 \% \\
\text { 3-years T2bN3: - } \\
\text { 3-years T3N2: } 4 \% \\
\text { 3-years T3N3: - } \\
\text { 3-years T2bN2: } 14 \% \\
\text { 3-years T2bN3: - } \\
\text { 3-years T3N2: } 9 \% \\
\text { 3-years T3N3: - } \\
\text { 3-years T2bN2 } 21 \% \\
\text { 3-years T2bN3 } 4 \% \\
\text { 3-years T3N2: } 18 \% \\
\text { 3-years T3N3: } 8 \% \\
\text { 3-years T2bN2: } 23 \% \\
\text { 3-years T2bN3: } 11 \% \\
\text { 3-years T3N2: } 18 \% \\
\text { 3-years T3N3: } 0 \% \\
\text { 3-years T2bN2: } 41 \% \\
\text { 3-years T2bN3: } 4 \% \\
\text { 3-years T3N2: } 11 \% \\
\text { 3-years T3N3: } 8 \% ; \\
\text { 3-years T2bN2: } 23 \% \\
\text { 3-years T2bN3: } 9 \% \\
\text { 3-years T3N2: } 52 \% \\
\text { 3-years T3N3: } 18 \% ; \\
\text { 3-years T2bN2: } 27 \% \\
\text { 3-y T2bN3: 13\% } \\
\text { 3-years T3N2: } 27 \% \\
\text { 3-years T3N3: } 13 \%\end{array}$ & $\begin{array}{l}\text { 3-years T2b-3N2: } 37 \% \\
\text { 3-years T2b-3N3: } 13 \% \\
\text { 3-years T2b-3N2-3: } 24 \% \\
\text { 3-years T2b-3N2: } 22 \% \\
\text { 3-years T2b-3N3: } 12 \% \\
\text { 3-years T2b-3N2-3: } 17 \%\end{array}$ & $\begin{array}{l}\text { For T2b-3N2: }<15 \text { LNs vs. } \geq 15 \text { LNs: } \\
3 \text {-years }=10 \text { vs. } 25 \%, P<0.0001 ;<20 \\
\text { LNs vs. } \geq 20 \text { LNs: } 3 \text {-years }=10 \text { vs. } 22 \%, \\
P<0.0001 ;<25 \text { LNs vs. } \geq 25 \text { LNs: } \\
3 \text {-years }=15 \text { vs. } 30 \%, P<0.0001 ;<30 \\
\text { LNs vs. } \geq 30 \text { LNs: } 3 \text {-years }=15 \text { vs. } 30 \%, \\
P=0.0014 \text {; for T2b-3N3: }<30 \text { LNs vs. } \\
\geq 30 \text { LNs: } 3 \text {-years }=5 \text { vs. } 15 \%, \\
P=0.0066 ;<40 \text { LNs vs. } \geq 40 \text { LNs: } \\
\text { 3-years }=7 \text { vs. } 10 \%, P=0.0339\end{array}$ \\
\hline $\begin{array}{l}\text { Siewert } \\
{[5]}\end{array}$ & $\begin{array}{l}>25 \text { LNs: } 1,096 \text { pts } \\
\quad(66.3 \%)\end{array}$ & $\begin{array}{l}\text { T1N0: 5-years }=81.4 \%^{\mathrm{b}} \\
\text { 10-years }=73.9 \%^{\mathrm{b}} \\
\text { T2N0: 5-years }=68.1 \%^{\mathrm{d}} \\
\text { 10-years }=48.0 \%^{\mathrm{d}} \\
\text { T2N1: 5-years }=27.9 \%^{\mathrm{f}} \\
\text { 10-years }=17.6 \%^{\mathrm{f}} \\
\text { T2N2: 5-years }=25.4 \%^{\mathrm{h}} \\
\text { 10-years }=21.1 \%^{\mathrm{h}} \\
\text { T4N0: 5-years }=0 \%^{\mathrm{j}} \\
\text { 10-years }=0 \%^{\mathrm{j}} \\
\text { T2N2: 5-years }=20.7 \%^{1} ; \\
\text { 10-years }=12.4 \%^{1} \\
\text { T1N0: 5-years }=84.3 \%^{\mathrm{b}} \\
\text { 10-years }=70.1 \%^{\mathrm{b}} \\
\text { T2N0: 5-years }=66.5 \%^{\mathrm{d}} \\
\text { 10-years }=54.8 \%^{\mathrm{d}} \\
\text { T2N1: 5-years }=51.1 \%^{\mathrm{f}} \\
\text { 10-years }=44.9 \%^{\mathrm{f}} \\
\text { T2N2: 5-years }=36.2 \%^{\mathrm{h}} ; \\
\text { 10-years }=21.3 \%^{\mathrm{h}} \\
\text { T4N0: 5-years }=42.9 \%^{\mathrm{j}} \text {; } \\
10 \text {-years }=28.6 \%^{\mathrm{j}} \\
\text { T2N2: 5-years }=13.5 \%^{1} ; \\
10 \text {-years }=9.8 \%^{1}\end{array}$ & $\begin{array}{l}\text { T1N1: 5-years }=83.3 \%^{\mathrm{c}} \\
\text { 10-years }=83.3 \%^{\mathrm{c}} \\
\text { T1N2: 5-years }=82.9 \%^{\mathrm{e}} \\
\text { 10-years }=82.9 \%^{\mathrm{e}} \\
\text { T3N0: 5-years }=53.1 \% \mathrm{~g} \\
\text { 10-years }=44.1 \%^{\mathrm{g}} \\
\text { T3N1: 5-years }=21.2 \% \text {; } \\
\text { 10-years }=14.5 \%^{\mathrm{i}} \\
\text { T4N1: 5-years }=12.5 \%^{\mathrm{k}} \\
\text { 10-years }=12.5 \%^{\mathrm{k}}\end{array}$ & $\begin{array}{l}P=\mathrm{NS}^{\mathrm{b}, \mathrm{c}, \mathrm{d}, \mathrm{e}, \mathrm{i}, \mathrm{k}, 1} \\
P=0.0037^{\mathrm{f}} \\
P=0.005^{\mathrm{g}} \\
P=0.032^{\mathrm{h}} \\
P=0.0006^{\mathrm{j}}\end{array}$ \\
\hline
\end{tabular}


Table 9 continued

\begin{tabular}{|c|c|c|c|c|}
\hline Study & $\mathrm{N}$ & Survival by combined TN stage & & Significance \\
\hline \multirow[t]{10}{*}{$\begin{array}{r}\text { Smith } \\
\text { [23] }\end{array}$} & $\begin{array}{l}\text { 1-9 LNs: } 2,143 \text { pts } \\
(56.5 \%)\end{array}$ & $\begin{array}{l}\text { 5-years T1/2N0: } 61 \%(95 \% \text { CI } \\
\text { 57-66) }\end{array}$ & $\begin{array}{l}\text { 5-years T3N0: } 33 \%(95 \% \text { CI } \\
\text { 29-37) }\end{array}$ & \multirow{10}{*}{$\begin{array}{l}\text { For }<10 \text { LNs vs. } \geq 10 \text { LNs: T1/2N0: } \\
\quad P=0.002 \\
\text { T1/2N1: } P<0.0001 \\
\text { T3N0: } P<0.0001 \\
\text { T3N1: } P<0.0001 \\
\text { For }<15 \text { LNs vs. } \geq 15 \text { LNs: T1/2N0: } \\
P=0.0048 \\
\text { T1/2N1: } P=0.001 \\
\text { T3N0: } P<0.001 \\
\text { T3N1: } P<0.001\end{array}$} \\
\hline & & $\begin{array}{l}\text { 5-years T1/2N1: } 33 \%(95 \% \text { CI } \\
25-40)\end{array}$ & $\begin{array}{l}\text { 5-years T3N1: } 14 \%(95 \% \text { CI } \\
\text { 12-17) }\end{array}$ & \\
\hline & $\begin{array}{l}\text { 10-19 LNs: } 1,153 \text { pts } \\
(30.4 \%)\end{array}$ & $\begin{array}{l}\text { 5-years T1/2N0: } 67 \%(95 \% \text { CI } \\
61-74)\end{array}$ & $\begin{array}{l}\text { 5-years T3N0: } 50 \%(95 \% \text { CI } \\
\text { 43-57) }\end{array}$ & \\
\hline & & $\begin{array}{l}\text { 5-years T1/2N1: } 51 \%(95 \% \text { CI } \\
41-61)\end{array}$ & $\begin{array}{l}\text { 5-years T3N1: } 25 \%(95 \% \text { CI } \\
20-29)\end{array}$ & \\
\hline & \multirow[t]{2}{*}{$\begin{array}{l}\text { 20-29 LNs: } 215 \text { pts } \\
\quad(5.7 \%)\end{array}$} & $\begin{array}{l}\text { 5-years T1/2N0: } 71 \%(95 \% \text { CI } \\
60-83)\end{array}$ & $\begin{array}{l}\text { 5-years T3N0: } 56 \%(95 \% \text { CI } \\
\text { 43-68) }\end{array}$ & \\
\hline & & $\begin{array}{l}\text { 5-years T1/2N1: } 65 \%(95 \% \text { CI } \\
50-80)\end{array}$ & $\begin{array}{l}\text { 5-years T3N1: } 33 \% \text { (95 \% CI: } \\
24-42)\end{array}$ & \\
\hline & \multirow[t]{2}{*}{$\begin{array}{l}\text { 30-39 LNs: } 215 \text { pts } \\
\quad(5.7 \%)\end{array}$} & $\begin{array}{l}\text { 5-years T1/2N0: } 87 \% \text { (95 \% CI: } \\
\text { 74-100) }\end{array}$ & $\begin{array}{l}\text { 5-years T3N0: } 58 \%(95 \% \text { CI } \\
37-79)\end{array}$ & \\
\hline & & $\begin{array}{l}\text { 5-years T1/2N1: } 25 \%(95 \% \text { CI } \\
0-67)\end{array}$ & $\begin{array}{l}\text { 5-years T3N1: } 42 \%(95 \% \text { CI } \\
\text { 26-57) }\end{array}$ & \\
\hline & \multirow[t]{2}{*}{$\begin{array}{l}>40 \text { LNs: } 67 \mathrm{pts} \\
\quad(1.8 \%)\end{array}$} & $\begin{array}{l}\text { 5-years T1/2N0: } 93 \%(95 \% \text { CI } \\
79-100)\end{array}$ & $\begin{array}{l}\text { 5-years T3N0: } 83 \%(95 \% \text { CI } \\
62-100)\end{array}$ & \\
\hline & & $\begin{array}{l}\text { 5-years T1/2N1: } 70 \%(95 \% \text { CI } \\
\text { 41-99) }\end{array}$ & $\begin{array}{l}\text { 5-years T3N1: } 50 \%(95 \% \text { CI } \\
\text { 30-70) }\end{array}$ & \\
\hline
\end{tabular}

$C I$ confidence interval, $L N$ lymph node, $N S$ not significant

\section{Survival}

Many studies show a difference in OS based upon the number of LNs examined. In univariate analysis, six of eleven cohorts found no survival difference according to the number of LNs assessed [5, 31, 43-45, 50]; while others showed that there was a significantly improved survival when $>10$ [34], $>15$ [49], or $>25$ LNs [47] were assessed (Table 3). Volpe et al. [47, 49]and Scartozzi et al. [47, 49] attributed the survival benefit to the close association of more LNs assessed with a D2 LN dissection [47, 49]. However, these studies also found that the survival benefit was highly stage-specific (stage 2 [5, 49]; stage 3 [44]); thus, the effect of stage migration cannot be ignored. If there is a true survival effect based upon the removal of additional LNs, this could be explained by the additional removal of disease. It is therefore reasonable that no significant survival difference was found in the $\mathrm{T} 1$ cancers, as these cancers have a significantly lower chance of $\mathrm{LN}$ involvement than higher T-stage cancers $[31,50]$.

In order to account for the effect of stage migration and to determine whether the assessment of more LNs yields a survival benefit, many authors have utilized multivariate survival modeling, incorporating both $\mathrm{N}$ stage and number of LNs assessed. In most of these models, survival is associated with both variables (Table 3). An increased number of LNs assessed was found to have a hazard ratio (HR) of death of 0.635 (95\% confidence interval [CI]
0.597-0.676) [24], 0.81 (95\% CI 0.76-0.87) [42], 0.76 (95\% CI 0.61-0.95) [46], and 0.59 (95\% CI $0.39-0.89)$ [47], and an odds ratio (OR) of survival of 3.7 (95\% CI 1.5-8.8) [34]. However, Giuliani et al. [38, 43] and Liu et al. $[38,43]$ found no difference in survival outcomes by number of LNs assessed. These conflicting findings fuel the debate of whether there is a true, independent positive effect of greater number of LNs removed versus the possibility that a confounding factor exists, such as extended $\mathrm{LN}$ dissection, that is associated with both the increased number of LNs removed and improved survival outcomes. An additional challenge for these analyses is making the assumption that the variables $\mathrm{N}$ stage and number of LNs assessed are fully independent, while in reality there may be significant interactions between these two variables, which may not be fully accounted for. Of note, none of the multivariable models to date reported testing for an interaction between the number of LNs assessed and $\mathrm{N}$ stage. While these studies do show a statistically significant association between survival and more LNs assessed, they cannot confirm causation.

The appropriate number of LNs to assess

While many studies found a significant difference in survival when $>15$ LNs were assessed, most only analyzed the data utilizing the cut-off point of $15 \mathrm{LNs}$ based upon the 5 th/6th edition of the UICC/AJCC staging manual. Many groups have suggested that the number of LNs assessed 
should vary according to stage and should be fewer than 15 LNs for early gastric cancer (EGC), and greater than 15 for more advanced cancers [30, 34, 50]. Lee et al. [29] found no significant stage migration for the stage Ia patients in their cohort based upon the number of LNs assessed. In comparison, in their analysis of EGC, Borie et al. [34] found that patients with $<10 \mathrm{LNs}$ assessed had significantly lower 5- and 7-year OS rates compared with patients with $\geq 10$ LNs assessed (Table 3). Siewert et al. [5] and Volpe et al. [49] found stage migration to be most prominent in stage II patients, while Karpeh et al. [18] and Liu et al. [44] found migration in stage III patients (Table 9), suggesting that a higher cut-off point of LNs assessed should be used for accurate staging in more advanced disease in an effort to avoid stage migration.

Smith et al. [23] and Schwarz et al. [25] have stated that the AJCC/UICC minimum goal of 15 LNs appears insufficient in the context of advanced-stage cancers [23, 25]. They recommend that the minimum goal should be set to at least ten LNs above the number of positive nodes, which would require at least $25 \mathrm{LNs}$ for patients with advanced nodal staging. Although other groups have suggested numbers as high as $40 \mathrm{LNs}$ assessed, a goal of 25 seems reasonable, even in the context of surgery performed in North America. Paradoxically, in Western countries it may be necessary to set the recommended number of LNs for dissection and assessment higher than 15 due to the advanced presentation of disease.

\section{Limitations}

There are many limitations to the data included in this review. All of these studies were retrospective; thus, there was no standard surgical or pathology protocol. There may be inherent differences in the patients receiving an extensive versus a limited $\mathrm{LN}$ dissection that are also associated with survival (i.e., co-morbid status, palliative resections, positive margins, institutional factors), and therefore the potential for unreported confounders continues to exist. The evaluation of the specimen for LNs, the histological evaluation of the node and methods to detect disease are also unaccounted for and introduce further potential bias to the studies being evaluated. Finally, a bias for publication of positive results may exist, decreasing the number of statistically non-significant results reported in the literature.

\section{Conclusion}

The extent of nodal involvement continues to be one of the most important prognostic factors for GC survival. Thus, an adequate number of LNs must be assessed to ensure patients are accurately staged and optimal treatment is prescribed. Population-based studies have indicated that the number of LNs assessed in each GC case varies, and in many cases is sub-optimal. From our systematic literature review of the data, we found that increased resection, tumor location, tumor size, and TNM staging information were all associated with a greater number of LNs assessed. With respect to long-term outcomes, patients with an increased number of assessed LNs have a better prognosis; however, much of this appears to be the effect of stage migration. Although current guidelines support a minimum number of $16 \mathrm{LNs}$ to be assessed for patients with GC, it is apparent that extensive dissections, nodal harvest, and pathological identification of more LNs limit the effects of stage migration. Therefore, a goal of more than $16 \mathrm{LNs}$ appears to be an appropriate target for surgery and pathological analysis.

Acknowledgments This research is funded by the Canadian Cancer Society (grant \#019325). Dr. Coburn has received the Career Scientist Award through the Ontario Ministry of Health and Long-Term Care. Dr. Law is supported by the Hanna Family Research Chair in Surgical Oncology.

\section{References}

1. Forman D, Burley VJ. Gastric cancer: global pattern of the disease and an overview of environmental risk factors. Best Pract Res Clin Gastroenterol. 2006;20(4):633-49.

2. Onate-Ocana LF, Aiello-Crocifoglio V, Mondragon-Sanchez R, Ruiz-Molina JM. Survival benefit of D2 lymphadenectomy in patients with gastric adenocarcinoma. Ann Surg Oncol. 2000;7(3):210-7.

3. de Gara CJ, Hanson J, Hamilton S. A population-based study of tumor-node relationship, resection margins, and surgeon volume on gastric cancer survival. Am J Surg. 2003;186(1):23-7.

4. Seto Y, Nagawa H, Muto T. Impact of lymph node metastasis on survival with early gastric cancer. World J Surg. 1997. 21(2):186-89 (discussion 90).

5. Siewert JR, Bottcher K, Stein HJ, Roder JD. Relevant prognostic factors in gastric cancer: ten-year results of the German Gastric Cancer Study. Ann Surg. 1998;228(4):449-61.

6. Bonenkamp JJ, Hermans J, Sasako M, van de Velde CJH. Extended lymph node dissection for gastric cancer. N Engl J Med. 1999;340(12):908-14.

7. Cuschieri A, Weeden S, Fielding J, Bancewicz J, Craven J, Joypaul V, et al. Patient survival after D1 and D2 resections for gastric cancer: long-term results of the MRC randomized surgical trial. Br J Cancer. 1999;79(9/10):1522-30.

8. Macdonald JS, Smalley SR, Benedetti J, Hundahl SA, Estes NC, Stemmermann GN, et al. Chemoradiotherapy after surgery compared with surgery alone for adenocarcinoma of the stomach or gastroesophageal junction. $\mathrm{N}$ Engl J Med. 2001;345 (10):725-30.

9. Kampschoer GH, Maruyama K, van de Velde CJ, Sasako M, Kinoshita T, Okabayashi K. Computer analysis in making preoperative decisions: a rational approach to lymph node dissection in gastric cancer patients. Br J Surg. 1989;76(9):905-8.

10. Bollschweiler E, Boettcher K, Hoelscher AH, Sasako M, Kinoshita T, Maruyama K, et al. Preoperative assessment of lymph 
node metastases in patients with gastric cancer: evaluation of the Maruyama computer program. Br J Surg. 1992;79(2):156-60.

11. Siewert JR, Kelsen D, Maruyama K, Feussner H, Omote K, Etter $\mathrm{M}$, et al. Gastric cancer diagnosis and treatment-an interactive training program. 1st ed. Springer Electronic Media; 2000. [Epub ahead of print]

12. Douglass HO Jr, Hundahl SA, Macdonald JS, Khatri VP. Gastric cancer: D2 dissection or low Maruyama Index-based surgery-a debate. Surg Oncol Clin N Am. 2007;16(1):133-55.

13. Hundahl SA, Macdonald JS, Benedetti J, Fitzsimmons T. Surgical treatment variation in a prospective, randomized trial of chemoradiotherapy in gastric cancer: the effect of undertreatment. Ann Surg Oncol. 2002;9(3):278-86.

14. Peeters KC, Hundahl SA, Kranenbarg EK, Hartgrink H, van de Velde CJ. Low Maruyama index surgery for gastric cancer: blinded reanalysis of the Dutch D1-D2 trial. World J Surg. 2005;29(12):1576-84.

15. Fleming I, Cooper J, Henderson D. AJCC cancer staging manual. 5th ed. New York: Springer; 1997.

16. Roder JD, Bottcher K, Busch R, Wittekind C, Hermanek P, Siewert JR. Classification of regional lymph node metastasis from gastric carcinoma. German Gastric Cancer Study Group. Cancer. 1998;82(4):621-31.

17. Ichikura T, Tomimatsu S, Uefuji K, Kimura M, Uchida T, Morita $\mathrm{D}$, et al. Evaluation of the New American Joint Committee on Cancer/International Union against cancer classification of lymph node metastasis from gastric carcinoma in comparison with the Japanese classification. Cancer. 1999;86(4):553-8.

18. Karpeh MS, Leon L, Klimstra D, Brennan MF. Lymph node staging in gastric cancer: is location more important than number? An analysis of 1,038 patients. Ann Surg. 2000;232(3):362-71.

19. Beahrs O, Henson D, Hutter R, Kennedy B. AJCC Manual for staging of cancer. 4th ed. Philadelphia: Lippincott; 1992.

20. Edge S, Byrd D, Compton C, Fritz A, Greene F, Trotti A. AJCC cancer staging manual. 7th ed. New York: Springer; 2010.

21. Rausei S, Dionigi G, Boni L, Rovera F, Dionigi R. How does the 7 th TNM edition fit in gastric cancer management? Ann Surg Oncol. 2011;18(5):1219-21.

22. Greene F, Page D, Fleming I. AJCC cancer staging manual. 6th ed. New York: Springer; 2002.

23. Smith DD, Schwarz RR, Schwarz RE. Impact of total lymph node count on staging and survival after gastrectomy for gastric cancer: data from a large US-population database. J Clin Oncol. 2005;23(28):7114-24.

24. Coburn NG, Swallow CJ, Kiss A, Law C. Significant regional variation in adequacy of lymph node assessment and survival in gastric cancer. Cancer. 2006;107(9):2143-51.

25. Schwarz RE, Smith DD. Clinical impact of lymphadenectomy extent in resectable gastric cancer of advanced stage. Ann Surg Oncol. 2007;14(2):317-28.

26. Marchet A, Mocellin S, Ambrosi A, Morgagni P, Garcea D, Marrelli D, et al. The ratio between metastatic and examined lymph nodes ( $\mathrm{N}$ ratio) is an independent prognostic factor in gastric cancer regardless of the type of lymphadenectomy: results from an Italian multicentric study in 1853 patients. Ann Surg. 2007;245(4):543-52.

27. Lee SR, Kim HO, Son BH, Shin JH, Yoo CH. Prognostic significance of the metastatic lymph node ratio in patients with gastric cancer. World J Surg. 2012;36(5):1096-101.

28. Latengbaolide A, Lin D, Li Y, Xu H, Chen J, Wang B, et al. Lymph node ratio is an independent prognostic factor in gastric cancer after curative resection (R0) regardless of the examined number of lymph nodes. Am J Clin Oncol. 2012 (Epub ahead of print).

29. Lee HK, Yang HK, Kim WH, Lee KU, Choe KJ, Kim JP. Influence of the number of lymph nodes examined on staging of gastric cancer. Br J Surg. 2001;88(10):1408-12.
30. Ichikura T, Ogawa T, Chochi K, Kawabata T, Sugasawa H, Mochizuki H. Minimum number of lymph nodes that should be examined for the International Union Against Cancer/American Joint Committee on Cancer TNM classification of gastric carcinoma. World J Surg. 2003;27(3):330-3.

31. Barbour AP, Rizk NP, Gonen M, Tang L, Bains MS, Rusch VW, et al. Lymphadenectomy for adenocarcinoma of the gastroesophageal junction (GEJ): impact of adequate staging on outcome. Ann Surg Oncol. 2007;14(2):306-16.

32. Coburn NG. Lymph nodes and gastric cancer. J Surg Oncol. 2009;99(4):199-206.

33. Hundahl SA. Staging, stage migration, and patterns of spread in gastric cancer. Semin Radiat Oncol. 2002;12(2):141-9.

34. Borie F, Plaisant N, Millat B, Hay JM, Fagniez PL. Appropriate gastric resection with lymph node dissection for early gastric cancer. Ann Surg Oncol. 2004;11(5):512-7.

35. Bouvier AM, Haas O, Piard F, Roignot P, Bonithon-Kopp C, Faivre J. How many nodes must be examined to accurately stage gastric carcinomas? Results from a population based study. Cancer. 2002;94(11):2862-6.

36. Bruno L, Nesi G, Montinaro F, Carassale G, Boddi V, Bechi P, et al. Clinicopathologic characteristics and outcome indicators in node-negative gastric cancer. J Surg Oncol. 2000;74(1):30-2.

37. Deng JY, Liang H, Sun D, Pan Y, Zhang RP, Wang BG, et al. Outcome in relation to numbers of nodes harvested in lymph nodepositive gastric cancer. Eur J Surg Oncol. 2009;35(8):814-9.

38. Giuliani A, Caporale A, Corona M, Di Bari M, Demoro M, Ricciardulli $\mathrm{T}$, et al. Lymphadenectomy in gastric cancer: influence on prognosis of lymph node count. J Exp Clin Cancer Res. 2004;23(2):215-24.

39. Huang CM, Lin BJ, Lu HS, Zhang XF, Li P, Xie JW. Effect of lymphadenectomy extent on advanced gastric cancer located in the cardia and fundus. World J Gastroenterol. 2008;14(26): 4216-21.

40. Huang CM, Lin JX, Zheng CH, Li P, Xie JW, Lin BJ, et al. Prognostic impact of dissected lymph node count on patients with node-negative gastric cancer. World J Gastroenterol. 2009; 15(31):3926-30.

41. Hundahl SA, Phillips JL, Menck HR. The National Cancer Data Base Report on poor survival of U.S. gastric carcinoma patients treated with gastrectomy: Fifth Edition American Joint Committee on Cancer staging, proximal disease, and the "different disease" hypothesis. Cancer. 2000;88(4):921-32.

42. Le A, Berger D, Lau M, El-Serag HB. Secular trends in the use, quality, and outcomes of gastrectomy for noncardia gastric cancer in the United States. Ann Surg Oncol. 2007;14(9):2519-27.

43. Liu C, Lu Y, Jun Z, Zhang R, Yao F, Lu P, et al. Impact of total retrieved lymph nodes on staging and survival of patients with gastric cancer invading the subserosa. Surg Oncol. 2009;18(4): 379-84.

44. Liu KJ, Loewen M, Atten MJ, Millikan K, Tebbit C, Walter RJ. The survival of stage III gastric cancer patients is affected by the number of lymph nodes removed. Surgery. 2003;134(4):639-44 (discussion 44-6).

45. Marchet A, Mocellin S, Ambrosi A, de Manzoni G, Di Leo A, Marrelli D, et al. The prognostic value of $\mathrm{N}$-ratio in patients with gastric cancer: validation in a large, multicenter series. Eur J Surg Oncol. 2008;34(2):159-65.

46. Marubini E, Bozzetti F, Miceli R, Bonfanti G, Gennari L. Lymphadenectomy in gastric cancer: prognostic role and therapeutic implications. Eur J Surg Oncol. 2002;28(4):406-12.

47. Scartozzi M, Galizia E, Graziano F, Catalano V, Berardi R, Baldelli AM, et al. Over-DI dissection may question the value of radiotherapy as a part of an adjuvant programme in high-risk radically resected gastric cancer patients. $\mathrm{Br} \mathrm{J}$ Cancer. 2005;92(6):1051-4. 
48. Shen JY, Kim S, Cheong JH, Kim YI, Hyung WJ, Choi WH, et al. The impact of total retrieved lymph nodes on staging and survival of patients with pT3 gastric cancer. Cancer. 2007;110(4):745-51.

49. Volpe CM, Driscoll DL, Douglass HO Jr. Outcome of patients with proximal gastric cancer depends on extent of resection and number of resected lymph nodes. Ann Surg Oncol. 2000;7(2):139-44.

50. Xu DZ, Geng QR, Long ZJ, Zhan YQ, Li W, Zhou ZW, et al. Positive lymph node ratio is an independent prognostic factor in gastric cancer after $\mathrm{d} 2$ resection regardless of the examined number of lymph nodes. Ann Surg Oncol. 2009;16(2):319-26.

51. Baxter N, Tuttle T. Inadequacy of lymph node staging in gastric cancer patients: a population-based study. Ann Surg Oncol. 2005;12(12):981-7.

52. Roukos D, Paraschou P, Lorenz M. Distal gastric cancer and extensive surgery: a new evaluation method based on the study of the status of residual lymph nodes after limited surgery. Ann Surg Oncol. 2000;7(10):719-26.

53. Mahar A, Qureshi A, Ottensmeyer A, Pollett A, Wright F, Coburn $\mathrm{N}$, et al. A descriptive analysis of gastric cancer specimen processing techniques. J Surg Oncol. 2011;103:248-56.

54. Songun I, Putter H, Kranenbarg E, Sasako M, van de Velde CJH. Surgical treatment of gastric cancer: 15-year follow-up results of the randomized nationwide Dutch D1D2 trial. Lancet Oncol. 2010;11:439-49.

55. Estes NC, MacDonald JS, Touijer K, Benedetti J, Jacobson J. Inadequate documentation and resection for gastric cancer in the United States: a preliminary report. Am Surg. 1998;64(7):680-5.

56. Bando E, Yonemura Y, Taniguchi K, Fushida S, Fujimura T, Miwa K. Outcome of ratio of lymph node metastasis in gastric carcinoma. Ann Surg Oncol. 2002;9(8):775-84. 